\title{
In Memoriam: Gerald Roy Patterson (1926-2016)
}

\author{
Per Holth ${ }^{1}$ (D)
}

Published online: 10 February 2017

(C) Association for Behavior Analysis International 2017

Gerald Roy Patterson (Fig. 1), a pioneer in behavior modification and a giant in behavioral research, died in his home in Eugene, Oregon, on August 22, 2016, at the age of 90. Dr. Patterson is most famous for his formulation of coercion theory, his research into the sources of antisocial behavior and delinquency in children, designing an intervention to prevent and treat those problems, and developing methods for direct observation of social interactions. When "Jerry" Patterson died, behavioral science lost one of its very best representatives. At 86, he published a book titled Free and Moving (Patterson, 2012), in which he described his two great passions: The first was his love for wilderness in its most extreme forms, and the second was his enduring search for answers to two important questions: (1) What causes aggression in children? (2) How can it be effectively treated? His basic work on the sources of child aggression has helped form the modern field of evidence-based interventions for prevention as well as for treatment of aggressive behavior in children and adolescents.

As a young man, Jerry Patterson worked as a canoe guide, which fit well with his first passion. At the age of 17, he joined the military services. Toward the end of World War II, Infantryman Patterson was sent to Okinawa, Japan, where after 3 months on duty, he was wounded; he was awarded the Bronze Star for heroism and the Purple Heart. His war experiences had a profound influence upon his interest in coercion and aggression in particular, and in a science of behavior in general. The G. I. Bill, which ensured education benefits for WWII veterans, made it possible for him to obtain an advanced education. He obtained his BA and MA at the University of Oregon (UO) in 1948 and 1951, respectively. While at the UO, he worked as a probation officer.

He received his $\mathrm{PhD}$ in psychology from the University of Minnesota in 1956, where he was exposed to the teachings of some great professors: Herbert Feigl taught the philosophy of Science, Paul Meehl taught courses on measurement and clinical processes and, finally, Kenneth MacCorquodale taught operant learning principles. From this training, he developed an interest in behavioral perspectives as well as a

Per Holth

per.holth@hioa.no

1 Oslo and Akershus University College of Applied Sciences, Oslo, Norway 


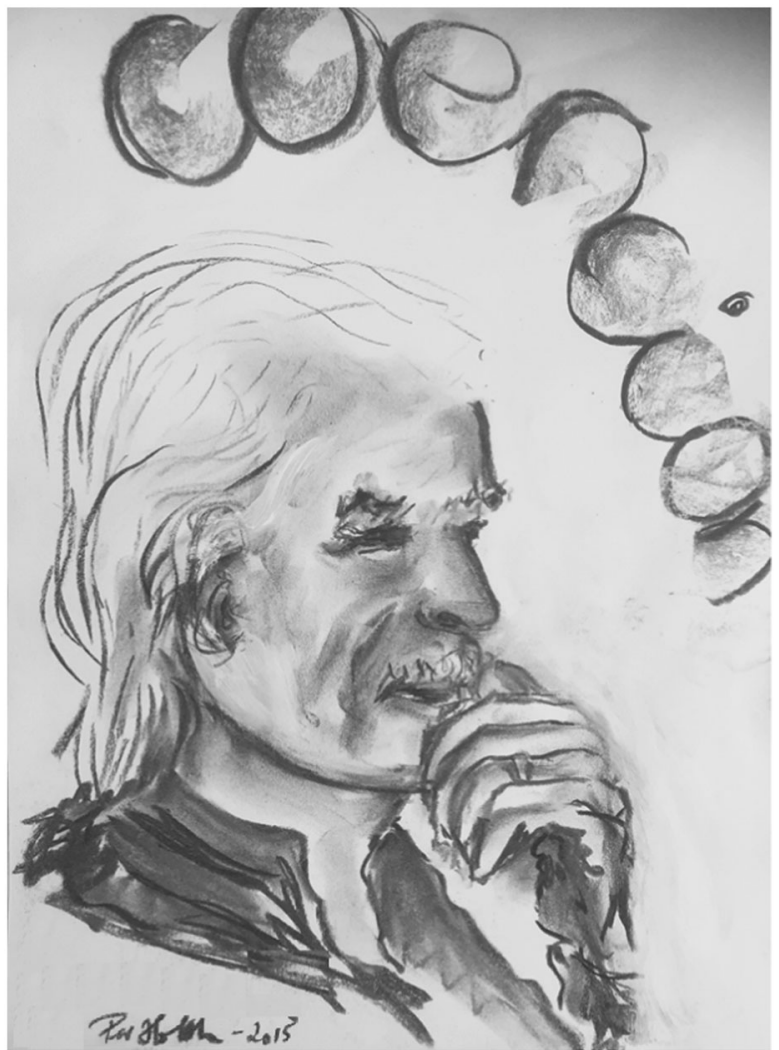

Fig. 1 Jerry Patterson

strong commitment to "making the world a better place." A variety of studies had suggested that, as causes of behavioral problems were sought in reinforcement contingencies, effective management of many behavioral problems could be developed by changing the environment in different ways. Another influence while he was earning his $\mathrm{PhD}$ came as he was a Fellow at the Wilder Child Guidance Clinic in Saint Paul. There, he received intensive training based on a psychodynamic perspective. The gross failure of that approach in treating young delinquents boosted his thinking that a better theory of aggression was necessary to arrive upon a more effective intervention.

An important event early in Patterson's career was a disease that threatened to make him blind. In his mid 30s, after he had accepted his fate and settled down as a clinical psychologist, a new technique of corneal transplantation came to rescue his vision and to open a whole new array of possibilities. This particular turn of events must have been important in shaping up the graciousness of this man, who was always generous in giving credit to his colleagues. Dr. Patterson joined the faculty of the Psychology Department at the University of Oregon, in 1956. When he and his colleagues started their research into basic questions about child aggression around 1960, there were several theories in the field, but none with a solid empirical base. Right away, their group found themselves in a squeeze between psychodynamic theory, developmental psychology, and social learning theory. Patterson's perspectives did not fit into any 
existing approach to child aggression. It seemed that most psychologists had been looking for explanations where no effective causes could be found: within the aggressive children in the form of frustration, lack of self-control, poor self-esteem, anxiousness, or lack of empathy. Although all these variables were found to correlate with aggression, none stood as a cause when tested as a potential change mechanism in the treatment of aggression. In the early seventies, Patterson and his colleagues had the great fortune to ask the right question at the right time, that is, "when the means existed to conduct a rigorous test of the hypothesis" (Patterson, 2012, p. 19). They started out with an emphasis on reinforcement contingencies and asked whether there are reinforcers for children's aggressive behavior and, if so, what are they?

This emphasis on reinforcement contingencies did not fit with the views of the establishment, particularly developmental psychologists who led a major attack on "reinforcement theory" (e.g., Bell \& Ainsworth, 1972). As Patterson pointed out, contingency arrangements are easy to misunderstand, and the developmental psychologists had missed a crucial part of the "equation." They had studied the probability of maternal responsiveness when infants cried, but ignored the probability of maternal responses when the infants had not cried. Social learning theories had focused on laboratory studies with contrived reinforcers, asking whether children's aggressive behavior toward Bobo dolls could be reinforced with M\&Ms. It could, but the studies provided no clue to what the reinforcers might be in the natural environment. After having joined a couple of such research fads over several years, Patterson and colleagues decided to make the natural social environment their "laboratory" by carefully collecting observational data there. After one of their first observation studies of children in a nursery school, they could state with considerable confidence that aggression was functional and that the victim was the key person who was training the aggressors by reinforcing their aggressive behavior. Hence, an effective therapy would have to change the social environment to stop the reinforcement. This new insight was met with considerable resistance from cognitively oriented colleagues at the psychology department. Jerry challenged them to suggest alternative practical solutions to the nursery school teachers who had to tackle aggressive behavior every day. They were unable to provide any such advice.

In 1967, Patterson escaped the conflicts over whether psychology was to be behavioral or cognitive by leaving his position as a tenured full professor in the psychology department at the University of Oregon. He moved to Oregon Research Institute (ORI), where time could be more effectively allocated to research. Ten years later, when conflicts took time and resources away from research even at ORI, he left there, too, and founded Oregon Social Learning Center (OSLC), where the Patterson group was free to conduct first-rate research their own way.

Although Jerry's work on solving the mysteries of aggressive child behavior was not driven by awards and honors, these inevitably started trickling in as the effects of his work spread. Perhaps, a peak was reached when the American Psychological Association awarded him with a Presidential Citation "for five decades of exemplary contributions to psychology."

When looking into G. R. Patterson's history, certain similarities with another great behavioral scientist, B. F. Skinner, are striking. In addition to their late starts in entering university programs, they were deeply interested in a science of behavior with the potential to contribute to making the world a better place, and both men made over their 
fields to suit themselves. Toward the ends of their lives, both wrote autobiographical texts, and both considered themselves as exemplars of behaving organisms and applied the behavioral principles to their own behavior. Hence, for example, they both established a routine out of getting up at 5 o'clock in the morning to start their daily work, and they recorded their own behavior extensively. Finally, they both emphasized the importance of luck in their careers. One of Skinner's "unformalized principles" of scientific practice was simply that "Some people are lucky," (Skinner, 1956, p. 225) and Patterson (2012) insisted that whereas luck is seldom mentioned in explanations of good science, in his own case, it was a key element right from the start.

One of those lucky events in Jerry's life must have been that he found his wife, Marion Forgatch. In fact, in his Free and Moving book, he devoted a special chapter to the topic, and he titled it "Finding Your Marion." They were to have more than 40 years together as partners and colleagues, filled with love, laughter, hard work, and intense play. Together, they did not hesitate to blaze a trail, in their exploration of wilderness or in scientific contributions. They continuously worked to improve on their Parent Management Training, the Oregon model (PMTO), to increase rigor in methods of direct observation, to find solutions when therapy failed, and to foster more effective implementation. When confronted with intractable problems, they did not hesitate to seek inspiration from colleagues with somewhat different perspectives. For example, in order to understand and to cope with resistance to treatment, they learned techniques from Paul Watzlawick, John Weakland, Carlos Sluzki, and others at the Mental Research Institute in Palo Alto. Exotic concepts, such as "mirroring," "paradoxes," and "positive connotations" crept into their vocabulary. Although a detailed behavioranalytic account of these phenomena may not yet exist, their relevance to clinical practice can surely be testified by any practitioner.

I cannot claim to have known Jerry Patterson very well, but I was one of many people who were fortunate to learn from his work and to meet him personally, as when he and Marion opened their home for a visiting group from Norway, working on the first nationwide implementation of PMTO in 2005. From the first moment, Jerry Patterson was a very likeable person, and he will be sorely missed. In addition to his wife Marion, Jerry Patterson left three sons, two daughters, two daughters-in-law, one son-in-law, and five grandchildren.

\section{Compliance with Ethical Standards}

Conflict of Interest The author declares that he/she has no conflict of interest.

\section{References}

Bell, S. M., \& Ainsworth, M. D. S. (1972). Infant crying and maternal responsiveness. Child Development, 43(4), 1171-1190.

Patterson, G. R. (2012). Free and moving. Eugene, OR: Author.

Skinner, B. F. (1956). A case history in scientific method. American Psychologist, 11, 221-233. 